\title{
"These forecasts may be substantially different from actual results." \\ The use of epistemic modal markers in English and German original letters to shareholders and in English-German translations*
}

\author{
Svenja Kranich and Andrea Bicsár (Hamburg)
}

\begin{abstract}
Letters to shareholders (i.e. the first part of a company's Annual Report) represent an interesting genre for the analysis of epistemic modal expressions. They serve the function to present a short overview of the company's main achievements as well as an outlook into the future. They additionally serve a more marketing-oriented goal: to inspire confidence in the company. Epistemic modal expressions (e.g. may, perhaps, probably) are used in texts for two main reasons: Firstly, speakers can signal with these markers that they have contentbased reasons to be unsure about the states of affairs they are talking about. This type of use can be expected to be typical in the context of predictions of future developments. Secondly, speakers can use them for interpersonal reasons, to open up the discursive space for alternative positions, leaving the readers their right to form their own opinion. This type of use can be expected in positive evaluations of one's own company, which are thus presented in a mitigated way, avoiding the impression of boasting.

It is in particular the second type of use that can be expected to be highly sensitive to cultural differences. The present paper analyzes to what extent US-English and German letters to shareholders differ in the use of these markers, and how these differences are reflected in English-German translations. Our quantitative analysis of the distribution of all epistemic modal markers in a multilingual corpus comes to the conclusion that there are notable differences between English and German original texts. Unlike in other studies on EnglishGerman translations (e. g. Kranich/House/Becher 2012), however, we arrive at the conclusion that the English-German translations are very closely adapted to the target-language conventions and show little interference from the English originals.
\end{abstract}

\section{Introduction}

In this paper we analyze the use of epistemic modal expressions (such as may, could, perhaps, probably) in American English and German letters to shareholders representing the first part of the Annual Report. The paper has a two-fold aim: firstly, we wish to establish contrasts in the use of such markers between letters written by large US-American and German companies. Secondly, on the basis of these contrastive results, we take a look at translation practice, with the following question in mind: to what extent are the translated texts adapted

\footnotetext{
* We would like to thank the two anonymous reviewers of the present article for their helpful comments. The study was enabled by generous funding from the DFG (German Research Foundation), which is hereby gratefully acknowledged. Special thanks is due to Martin Schweinberger for his help with the statistical analysis.
} 
to the conventions of the target language community and to what extent do they reflect communicative practices of the source language community?

Epistemic modal markers represent an interesting field of investigation, because such markers can be used for two different reasons. Use of epistemic modal marking can be either contentoriented or addressee-oriented (cf. Hyland 1996, 1998; White/Sano 2006). In the first case, the speaker simply does not have enough information about the states of affairs (SoAs) s/he is talking about. In the second case, the speaker feels sure enough about the truth of what $\mathrm{s} / \mathrm{he}$ is saying, but chooses to use epistemic modal marking as a hedging strategy. That is, s/he presents the truth of the proposition as only possibly or probably true in order to leave room for other opinions, not to affront the addressee or not to lose the addressee's sympathy. ${ }^{1}$

One should note in this context that the notion of hedging encompasses a wider array of linguistic means than just epistemic modal markers. The term typically refers to all linguistic strategies/linguistic markers that allow the speaker to weaken the force of a proposition. Common strategies to achieve this are, on the one hand, vague expressions (e. g. kind of, sort of), on the other, linguistic means that allow the speaker to make a weaker claim about the truth of the proposition (cf. Hyland 1996, Markkanen/Schröder 1997: 4-8). Epistemic modal markers are typical devices employed for the latter purpose (Mauranen 1997: 115f.). The advantage of limiting the present corpus analysis to epistemic modal markers only is that this makes the delimitation of the object of study more clear-cut. As Clemen (1997: 242) has pointed out: "Researchers cannot agree on which lexical items, phrases or syntactic structures should be classed as hedges [...] There are no clear criteria" (cf. also Mauranen 1997: 116). A study of epistemic modal markers, which can be defined as elements that modify the truth value of a proposition, is thus a more feasible endeavor, especially if one is interested in generalizable quantitative results.

Let us now take a look at an example of the content-oriented type (Example (1)) and of the addressee-oriented type (Example (2)):

(1) In North America, early indications suggest the level of economic activity is likely to plateau in 2000 following another year of rapid growth in 1999. (DaimlerChrysler 1999)

(2) Perhaps that's why we have one of the lowest staff turnovers in our industry and are rated as one of the world's most attractive employers. (DaimlerChrysler 1999)

In the first example, the author makes a prediction about a future event, which he has no way to be absolutely certain of. The use of the epistemic marker is likely to is thus contentoriented. The author of the assertion in (2), on the other hand, can be assumed to use the epistemic marker perhaps rather than the unmodified version of the assertion not only because he cannot be completely certain whether what he presented before is really the reason for the positive result described, but also because presenting such a high praise of one's own company without any form of hedging might lead to an unfavorable impression of arrogance and aggressive self-promotion. The use thus has at least an interpersonal component.

\footnotetext{
${ }^{1}$ Hyland (1996: 437) actually proposes a more fine-grained classification than merely the distinction between content-oriented and addressee-oriented hedges, distinguishing e.g. between accuracy-oriented hedges (concerned with presenting the information as accurately as possibly) and writer-oriented hedges (which are used in passages where the writer is reasoning, e. g. in statements such as The figures suggest that...). Hyland (1996: 439) himself, however, stresses the indeterminacy and overlap between these categories. It would thus hardly be feasible to apply this fine-grained distinction in a quantitative corpus-based approach such as the present one. In fact, as explained further on in this section, it often does not even seem possible to make a clear, unequivocal distinction between the two main types, content-oriented and reader-oriented hedges.
} 
"These forecasts may be substantially different from actual results."

The use of epistemic modal markers in English and German original letters to shareholders and in English-German translations

Concerning this latter type of use, it is plausible to expect notable cultural differences. In the addressee-oriented, interpersonal use of modal marking, politeness norms and cultural conventions concerning acceptable levels of directness/indirectness and of self-assertion come into play. Cultural differences between (American) English and German relating to such factors have been shown to exist in various contrastive and translation-oriented studies of business communication (e.g. McCallister/Bates 1986; Byrnes 1986; Clyne 1987; Jenkins/Hinds 1987; Bolten et al. 1996; Böttger/Bührig 2003, 2007; Baumgarten/Özçetin 2008). Anecdotal evidence exists which suggests that English language reports are more tentative than German ones. A financial specialist reports: "When we get reports from the Germans for instance they say they will do this they will do that... we soften all that." (quoted by Pindi/Bloor 1987: 58).

The importance of cultural adaptation in this area should not be underestimated, since the use of more or less hedging in a text has been shown to have significant effects on readers. Crismore and Vande Kopple (1997) have found out that the use of hedges has clear positive effects in the transmission of controversial ideas. Texts with hedges were shown to foster a more positive development in attitude towards new ideas than unhedged versions of the same text. Furthermore, the use of hedges increased the motivation to continue reading, and the authors of texts with many hedges were perceived as warmer. The same study showed that hedging also has its drawbacks: when the use of hedges is perceived as excessive, readers doubt the competence and the believability of the author. It is therefore of utmost importance for a text type as the letter to shareholders, with its central aim of inspiring trust and confidence in the readers, to strike the right balance. On the basis of the quantitative results on actual usage in English and German originals, our comparison of current English-German translated letters to shareholders to German originals will therefore help to provide wellgrounded suggestions for improvements in translator training and translational practice in international companies.

The paper is structured as follows: after this introduction some previous results on differences in communicative preferences between English and German will be presented. We will then provide a brief overview of the function and structure of letters to shareholders in the USAmerican and the German business culture. This will be followed by some remarks about how epistemic modal marking is used in this particular text type. After presenting our methodology and the corpus of texts we used for our investigation, we will provide the quantitative results of our analysis and discuss their relevance, and will conclude by presenting a summary of the results.

\section{English-German communicative contrasts}

Differences between English (both American and British English) and German have been discovered with respect to many different types of discourse. The table below summarizes the main results:

English

shows a tendency towards...

Indirectness

Orientation towards persons

Orientation towards addressee

Implicitness

Verbal routines
German

shows a tendency towards...
Directness
Orientation towards content
Orientation towards self
Explicitness
Ad-hoc-formulation 
more interactional discourse

more involved discourse more transactional discourse

more detached discourse

Table 1: Communicative preferences in English and German texts (based on House 1996, 2006)

The English texts, whether produced by British or American authors, thus show a tendency to be less direct than German texts and to involve the addressee to a greater extent. Both these points can be expected to have an influence on the frequency of epistemic modal markers in texts, since such markers make texts less direct (presenting assertions with less force) and more addressee-oriented (leaving more room for other opinions).

The greater addressee-orientation of English texts has been shown for instance in a study on the use of sentence-initial but and aber (cf. Becher/House/Kranich 2009) in popular scientific texts. The use of the sentence-initial conjunction can make a text more addressee-oriented, in that it simulates a face-to-face interaction in the text. The study showed that the sentenceinitial conjunction is more typical of English than of German original texts, but that EnglishGerman translations show a certain 'shining-through' (Teich 2003) of the English norms and that this higher use of sentence-initial conjunctions in English-German translations even appears to trigger a more common use of them in German original texts over time presumably because the English texts and the English-German translations function as a prestigious model in the genre of popular science, which is longer established in the United States than in Germany (Baumgarten 2008: 410). The cultural filter, normally applied in translations to make them correspond more to target text conventions (cf. House 1997), is therefore applied less (cf. also House 2007, Kranich/House/Becher 2012).

The use of epistemic modal marking in English and German originals and translated texts has been investigated in the genre of popular scientific writing, which brought to light the contrasts one could expect: English originals use much more epistemic modal marking than German texts, in particular markers of low certainty (such as maybe, in contrast to markers such as probably which mark higher certainty) (cf. Kranich 2011a). One can expect that authors from both cultures use epistemic modal markers where they are really not sure about the truth of the proposition, but that they differ in respect to the addressee-oriented type of use. In the same study, English-German translated texts are shown to exhibit frequencies in between English originals and German originals, which points towards a translation strategy characterized partly by shining-through of source language norms, partly by adaptation to target-language norms (Kranich 2011a, cf. also Kranich 2009, which shows how translators adapt texts to the target language norms in this area).

Finally, in a purely contrastive analysis of English, German and French texts, Kranich (2011b) has already established that there are contrasts between English and German use of epistemic modal markers in letters to shareholders. However, the exact (statistically calculated) extent of the quantitative effects was not yet considered, nor was an analysis of the way translators handle these contrasts effected. Thus, the results of previous studies make the present investigation seem a very worthwhile endeavor: we will be able to see to what extent the same tendencies visible in popular scientific writing hold here, in spite of the vastly different aims of the two genres, ${ }^{2}$ and if the translation strategies are similar between these two genres.

\footnotetext{
2 Popular scientific texts can be said to pursue the aim of presenting new information to the readers in an accessible and entertaining way. The hedging use of modal marking can be expected to be necessary in this genre to make sure that the reader does not feel coerced into giving up his old views of the state-of-the-world in favor of the new ones presented in the text (cf. also Wilke 1986: 312). Hedging would appear to be particularly necessary in cases in which the popular scientific text presents the reader with rather unlikely sounding
} 
"These forecasts may be substantially different from actual results."

The use of epistemic modal markers in English and German original letters to shareholders and in English-German translations

\section{The function and structure of letters to shareholders}

The text type we call 'letters to shareholders' in this paper represents the first part of the Annual Report. The letter functions both as introduction and as synthesis of the following collection of documents. Next to this information-conveying function, the letter has functions related to marketing: it aims at presenting a positive image of the company to (present and potential) shareholders ${ }^{3}$ (see the descriptions of the text type by Fløttum 1998, Hyland 1998 and Garzone 2004, 2005).

The letter to shareholders plays a very important role in the communication between companies and shareholders, as it represents the most widely read part of the whole Annual Report (Kohut/Segars 1992), especially when it comes to less-specialized readers (Garzone 2004: 321). So it is of great importance to choose the right expressions and find the right tone of voice to convey a positive image of the company, in order to avoid negative shareholder reactions.

The structure of the letters is comparable in the American English and the German business cultures. In the terms of Swales' (1990) genre analysis, one finds the following "moves" in both cultures:

1. An evaluation of the performance of the company in the relevant year

2. A narrative of the events and results of the relevant year considered most important

3. A declaration of priorities for the future and predictions of future performance

(Garzone 2005: 194)

While all three moves are present in both American English and German letters, there are also some differences in the typical organization of the letters. For instance, one notes a certain tendency to present more general evaluative statements in the American letters. Moves 1 and 3 in the model presented above thus take up more space in the American letters than in the German letters, which puts more weight on the detailed account of concrete events and facts that characterizes move 2. The following instance presents an example of such a "typical American" use of general positive evaluation, which has almost the character of a slogan:

(3) Our business is more than just our products and services. It's about an experience. (DaimlerChrysler 1999)

The results of this qualitative analysis thus indicates that the US-letters seem to put more emphasis on conveying a positive image, by making use of positive connotations and slogans, while the German letters put greater weight on the description of tangible results. If one takes it that the function of the genre 'letter to shareholders' is double, i. e. partly informative, partly persuasive, we could say that the persuasive marketing component is stronger in the USbusiness culture (cf. Kranich 2011b: 117-118). We will see in the quantitative section

information, e.g. the possibility of future harvesting on the moon. Letters to shareholders, on the other hand, have the two-fold aim of presenting information and of conveying confidence. They must strike the right balance between reliable information and marketing. The hedging use of epistemic modal marking in letters to shareholders can thus be expected in cases where negative news need to be conveyed, as a softener, and also in cases such as the one in (2), where the absence of hedging would lead to an unfavorable impression of arrogance.

3 These documents are generally published online these days, so they are accessible to a great number of people. The letters are nevertheless mostly aimed at the present shareholders and at professional share sellers at the banks. 
(Section 5) to what extent these global differences in the structure are reflected in quantitative results concerning the use of epistemic modal expressions.

\section{$4 \quad$ Functions of epistemic modal expressions}

Epistemic modal expressions, as pointed out above, can serve both content-oriented and addressee-oriented functions. The content-oriented function is rather clear-cut. As many studies on the semantics of modal expressions have stated, epistemic modality serves to indicate that the speaker is not fully certain that the propositional content of the clause is true (cf. e. g. Palmer 2001: 8; Van der Auwera et al. 2005: 201; Verstraete 2007: 17). Epistemic expressions thus attribute less than full truth value to the proposition (cf. Larreya 2009: 13), i. e. they mark a proposition as not certainly true, but only probably or possibly true (cf. also Declerck 2009: 48). What is more interesting to us in the context of intercultural communication and translation is that these markers can also fulfill an interpersonal function. They can serve as a means of hedging, making assertions in a text less forceful and hence less threatening to the addressee. Consider the use of may in the following example, taken not from our corpus, but from the world-wide web:

(4) An individual may have a problem with alcohol if there is constant obsessing about drinking, repeated attempts and failure to stop on his/her own, or often drinking more than planned. (http://www.alcoholanswers.org/friends-family/recognizing-theproblem.cfm, accessed September 22, 2012)

Objectively speaking, it is not really a mere possibility that an individual fulfilling the listed conditions has a problem with alcohol, but rather almost a certainty. Why does the author still choose to use may which conveys that the truth of the proposition is merely a possibility? One can be fairly certain that interpersonal reasons are responsible: if a reader with an alcohol problem browses through the website, they will be much more likely to accept the statement that they may have a problem with alcohol than that they have a problem. The author of the website is thus much more likely to reach his/her intended communicative goal of provoking at least some thought about the issue or even getting people to seek help. This goal would not be reached if the addressee has a strong adverse reaction to the statement even if it is true.

The possibilities for hedging are vast. It can be achieved by a variety of linguistic means and it can serve different face-saving functions (cf. Hyland 1996: 437). In example (4) it tries to spare the reader by making a negative proposition about him/her less forceful. It can also save the face of the writer, by making a positive proposition about him/her more vague. This can either help to make the writer appear less self-praising (as in example 2), or it can save the writer from being accused of false promises, as in the example below (also retrieved from the internet):

(5) We have all the possibilities to offer our customers an overall solution to their needs for complete electrical automation.

(http://www.jonecsystem.com/index.php?id=23\&L=1, accessed September 22, 2012)

The proposition this example contains is rather vague, i. e. it is difficult to know under which exact conditions it can be said to be true. The example comes from a similar text type as the one investigated here, namely from the self-presentation of the company Jonec on their website. The message conveyed presents a very positive self-image and it implies a promise: since we have all the possibilities to offer a solution, we will offer a solution. This is, however, only an implicature, and not explicitly verbalized. This type of vagueness can also be counted as hedging, and it would be very interesting to try to investigate the various strategies used for this purpose in the genre letters to shareholders, as such rhetoric strategies are very commonly used in this genre. However, in a quantitative corpus analysis, one also needs a clear-cut definition as to what to retrieve. As stressed in the introduction, this is 
"These forecasts may be substantially different from actual results."

The use of epistemic modal markers in English and German original letters to shareholders and in English-German translations

difficult to attain with regard to the vast and diverse category of hedging strategies. Epistemic modal markers, on the other hand, can be captured using the following definition: an epistemic marker is an expression that indicates that the speaker does not express full certainty concerning the truth of the proposition (Coates 1995: 59). Epistemic marking can be achieved by a variety of linguistic means, from more grammatical expressions (e. g. modal adverbs such as probably, modal verbs such as might) to more lexical expressions (e.g. it is expected that, we believe that).

As noted above, one can distinguish two motivations that play a role in the choice of epistemic modal marking in discourse: either the speaker is really not sure about the SoAs in the reference world, or $\mathrm{s} / \mathrm{he}$ has communicative, interpersonal reasons for acting as if $\mathrm{s} / \mathrm{he}$ entertains some doubt. Both motivations can be expected to play a role in the text type we are investigating. A straight-forward analysis of the corpus instances, deciding in each case whether we are looking at a content- or addressee-oriented use is not possible: the division is too fuzzy, as Hyland (1996: 437-439) also points out. Thus, a mostly content-oriented hedge may also have an additional interpersonal motivation, while a mostly reader-oriented hedge might also be used to some extent for content-related reasons.

What lets us nevertheless glean some insights about the relation between (mostly) contentand (mostly) reader-oriented use in the three subcorpora may be the distribution of epistemic modal markers across the tenses. In the letters to shareholders, the company presents both an overview of past results and the present state of the company and predictions about its future development. Concerning past and present achievements, it is reasonable to assume that the author/s of the letters mostly have access to sufficient information to be certain about the truth of what they are asserting. The use of epistemic modal markers in past and present contexts will thus typically be interpersonally motivated, as in example (2) above (Perhaps that's why we have one of the lowest staff turnovers in our industry). When predictions about future events are made, on the other hand, the company has no way of being absolutely certain that what they are predicting will come to pass. Use of epistemic modal marking in such contexts is therefore very likely to be content-related, as in example (1) above (In North America, early indications suggest the level of economic activity is likely to plateau in 2000). Similarly, we can assume that authors can generally rely on more certain information when speaking about the company itself, both in future, present and past contexts, while with regard to assertions about SoAs outside the company, again such as the one in example (1), authors will typically have a more limited access to all relevant information. These two factors, temporal reference and reference to SoAs within or without the company itself, will be investigated more closely in the present study, in order to see whether there are differences between English and German texts that can be related to different cultural norms regarding the appropriate level of hedging, and if there are, how translators deal with them.

\section{$5 \quad$ Corpus and methodology}

\subsection{The Corpus of Letters to Shareholders}

The corpus consists exclusively of letters to shareholders, i. e. the first part of the Annual Report. We have chosen original (i. e. non-translated) American English and German texts, and texts translated from American English into German. In order to take into account all epistemic expressions, regardless of their more grammatical or more lexical status, it was necessary to conduct a close-reading analysis of the texts. An automatized corpus search would necessarily have been limited to pre-chosen expressions and thus would have limited the field of investigation. In order to make this method feasible, we have limited the size of 
the subcorpora to around 40,000 words each, i. e. aroun 120,000 words on the whole. The exact numbers can be gathered from the table below:

\begin{tabular}{|l|l|}
\hline & Words \\
\hline English Originals & 38,325 \\
\hline English-German translations & 37,290 \\
German originals & 41,729 \\
\hline
\end{tabular}

Table 2: The Corpus of Letters to Shareholders

In the process of corpus compilation, specific care was taken to ensure representativeness across the wide business spectrum, by choosing high-performance companies from different sectors (i.e. economy, food, leisure, automobile, energy etc.). Comparability of the subcorpora is ensured by the same means, i.e. firstly, by choosing high-performance companies, which can be assumed to represent the going standard and to take great professional care of providing adequate translations, and secondly by choosing letters from companies from the same broad spectrum of sectors for each subcorpus. The status of the translations in the corpus is that of official translations which are sent out to the shareholders and presented on the company's website. It can thus be assumed that significant care was taken in the translation process and that professional translators were at work. We are stressing this point in order to underline that even marked translation choices cannot be dismissed as simply 'bad translations'. Rather, even when we look at unusual translations, we should assume that the translator aimed at producing a specific effect. In any case, the corpus compilation is such that the texts in the corpus can be considered representative of the genre 'letters to shareholders', and even though the corpus is small, the number of epistemic modal markers retrieved from each subcorpus is sufficient to prevent any unusual use in an individual text from potentially falsifying the overall results.

\subsection{Methodology}

For our analysis we have extracted all epistemic modal expressions according to the definition presented above: that an epistemic modal marker is an element in an utterance that makes clear that the speaker asserts only that it is possible or probable that the proposition is true. That means, cases such as (1) and (2) were included, because in cases like these, one can clearly identify an element that marks the truth of the proposition as only possible or likely (is likely to in (1), perhaps in (2)). Cases where assertions are merely vague, as in example (5) above (We have all the possibilities to offer our customers an overall solution) were not included.

A more fine-grained analysis is needed to allow us to see which kind of uses are responsible for different overall frequencies. After having isolated the elements we are considering as epistemic modal expressions in this way, we therefore classified these expressions according to the following three factors (following the analysis conducted by Kranich 2011b):

1. Grammatical category of the expression

2. Temporal reference of the expression

3. Reference to the company itself/reference to SoAs outside the company 
The first factor has been chosen because its inclusion provides us with general insights on contrasts between the three languages concerning the functional field of epistemic modal marking. The second and the third factor have both been included in order to enable us to draw conclusions about content- vs. reader-oriented uses of epistemic modal markers. The quantitative results are all tested as to their significance using chi ${ }^{2}$-statistics.

\section{Epistemic modal marking in our corpus of Letters to Shareholders}

\subsection{Overall frequencies}

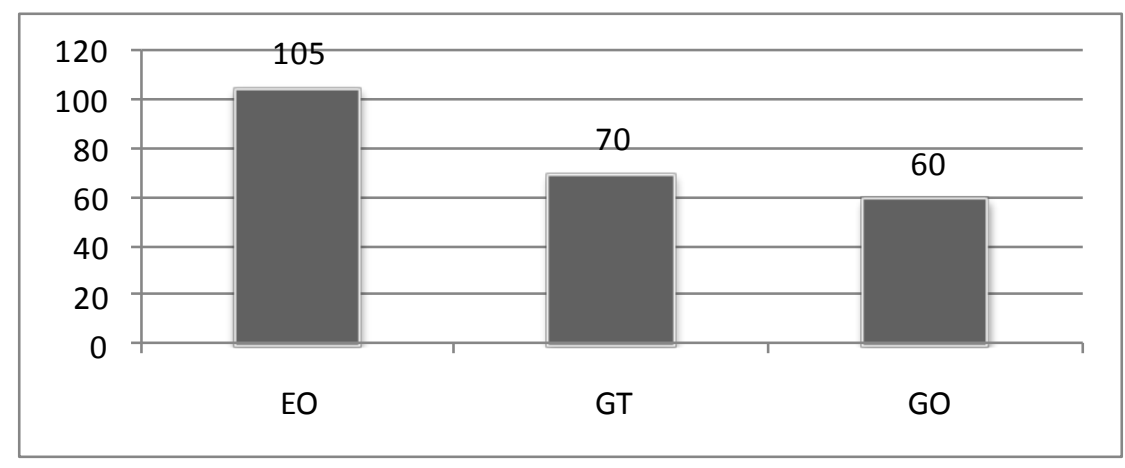

Figure 1: Total number of occurrences of epistemic marking

As figure 1 shows, there are clear quantitative differences in the number of total occurrences of epistemic modal items in English originals (EO) and German original texts (GO) analyzed in the present study. The chi²-test performed on these figures (calculating the relation between epistemic modal expressions on the basis of total number of words per subcorpus) shows that the differences between EO and GO are highly significant $(\chi=16.461$, df $=1, \mathrm{p}<0.001, \varphi=$ 0.014). EO also differ significantly from German translations (GT), but the difference is less pronounced $(\chi=6.089$, df $=1, p<0.05, \varphi=0.08)$. The less pronounced nature of the difference can be regarded as a consequence of a certain degree of shining-through. However, the difference in overall frequencies between GT and GO is not significant, which shows us that the translations are quite successfully adapted to target language discourse norms. Frequency of modal marking is thus significantly higher in English than in German texts of this genre, with the German translations showing only a slight, non-significantly higher use of epistemic modal marking than German original texts.

\subsection{Grammatical categories realizing epistemic marking in the corpus}

A diverse set of linguistic devices is used to express epistemic modality in the texts analyzed here, including modal verbs, adverbs, adjectives and particles as well as lexical verbs and phrases, such as e. g. we assume that or it is to be expected that. Figure 2 shows the number of occurrences of the different grammatical categories throughout the English and German originals as well as German translations of letters to shareholders. 


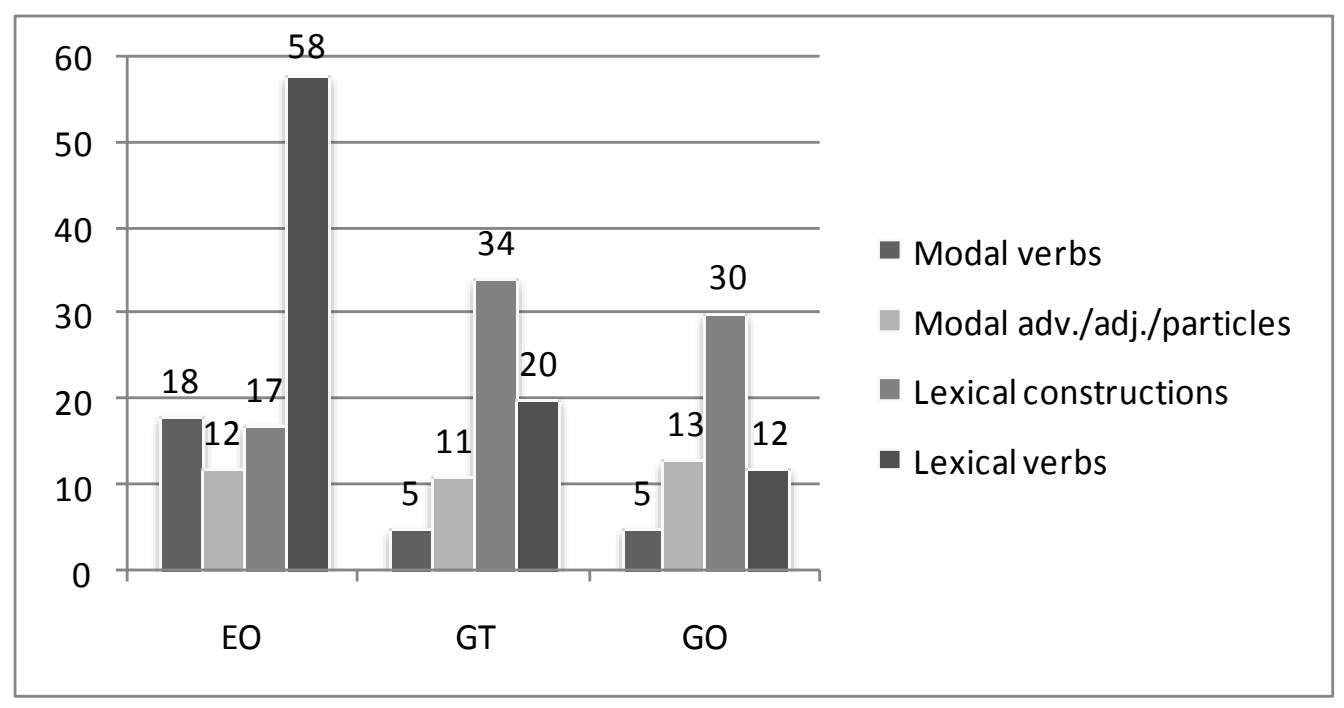

Figure 2: Distribution of epistemic markers according to grammatical category

As figure 2 indicates, English letters to shareholders favor the use of lexical verbs to mark epistemic modality. In more than half of all instances the authors modify the degree of certainty with which the proposition is asserted by constructions consisting of a first person pronoun plus a verb of believing, as illustrated by examples (6) and (7): ${ }^{4}$

(6) We expect the Organization 2005 program to increase long-term sales growth to 6-8 $\%$. (P\&G 1999)

(7) We believe that our audits provide a reasonable basis for our opinion. (ADM 1999)

As opposed to the marked preference for this use in English, in German letters to shareholders greater variation can be observed. The high use of lexical verbs is thus characteristic of the discourse norms of the genre in English. The chi²-test shows this to be a significant difference between EO and both GO and GT ( $p<0.001$ in both cases). ${ }^{5}$ However, the effect strength is greater between EO and GO $(\varphi=0.342)$ than between EO and GT $(\varphi=0.262)$, which may suggest a slight degree of shining-through. However, GT and GO again do not differ significantly from each other in this respect, so that the translations can be said to be welladapted to German textual conventions in this respect as well.

\subsection{Temporal reference}

As noted above, temporal reference was included in the analysis to see to what extent the use of epistemic modality serves a content-oriented and to what extent it serves an addresseeoriented purpose in the texts. Findings concerning temporal reference in modalized sentences are summarized in figure 3 :

\footnotetext{
${ }^{4}$ All examples cited in this section are taken from the corpus of the present study.

5 The exact results of the comparison of lexical verbs vs. all other modal expressions are for EO vs. GT: $\chi$ $=12.089, \mathrm{df}=1, \mathrm{p}<0.001 * * *, \varphi=0.262$, for EO vs. GO: $\chi=19.410, \mathrm{df}=1, \mathrm{p}<0.001 * * *, \varphi=0.342$.
} 


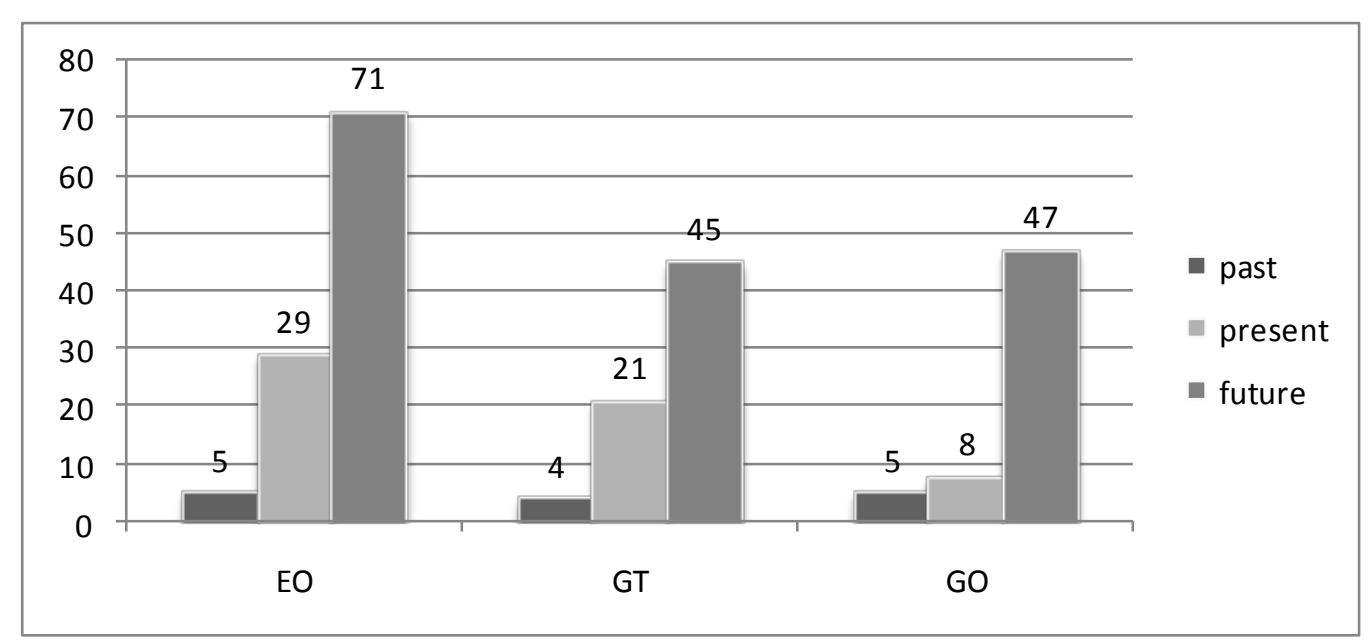

Figure 3: Distribution of epistemic modal markers according to temporal reference

Since prognoses of future developments of a company form an inherent part of letters to shareholders and future events are - indeed - not predictable with absolute certainty, it does not come as a surprise that all text types analyzed here use epistemic modal expressions mostly in statements referring to the future of the company. In the majority of instances, we may conclude that epistemic marking is used in a content-oriented way, since the author cannot be absolutely sure about the content of a proposition presenting future events. As far as statements about the present and the past are concerned, on the other hand, epistemic modal use can be assumed to be more often interpersonally motivated, since the speaker is more likely to possess enough information to formulate the proposition with assurance.

The present analysis shows that the proportion of epistemic modal expressions in present and past contexts is somewhat higher in the US-English texts $(32.4 \%)$ and in the German translations (35.7\%) than in German original texts $(25.0 \%)$. We could assume that this result reflects the tendency of English letters to shareholders to be more addressee-oriented than German originals of the same genre (a finding in line with results from previous research on this genre and on contrasts in popular scientific writing, summarized in Section 2). However, the results are not generalizable, as they fall short of real statistic significance. The difference between English and German originals does not turn out to be significant, while, interestingly, the slightly greater difference between German translations and German originals can be said to be marginally significant $(\chi=3.081, \mathrm{df}=1, \mathrm{p}=0.078, \varphi=0.153)$.

In the following section we shall see whether reference to the company and to SoAs outside the company reveal contrasts between the use of epistemic modality in English and German letters to shareholders.

\subsection{Reference to state-of-affairs related and not related to the company}

In this last step of our analysis, we distinguished between SoAs that hold within the company or are closely related to events in the company, and those that are not related to the company. Example (8) illustrates a sentence presenting a statement about the company, while (9) exemplifies the portrayal of developments outside the company:

(8) We remain convinced that we have an effective financial services business model. (GE 2008)

(9) By 2017, we forecast that today's emerging markets will account for more than half of industry unit sales, and our plan is to play a major role in this growth. (GM 2007) 
Results of this analytic step are summarized in figure 4:

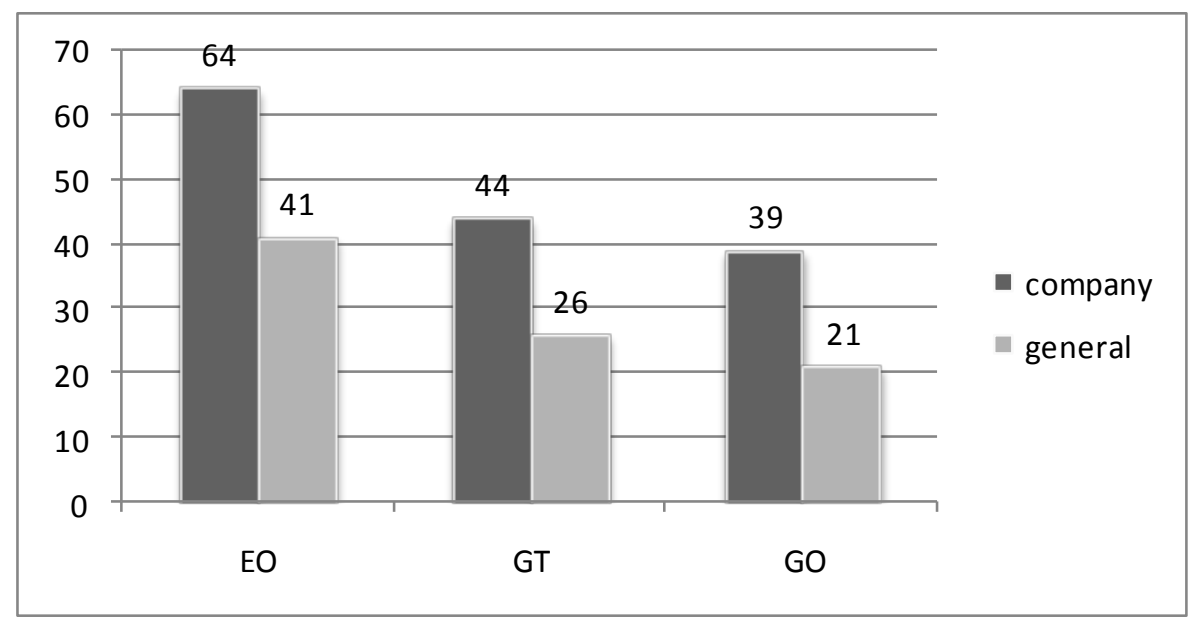

Figure 4: Distribution of epistemic modal markers according to SoAs within and outside of the company

As figure 4 illustrates, English as well as German originals and English-German translations of the corpus tend to make more frequent use of epistemic elements in statements about the company itself. This can be assumed to reflect the fact that a much greater proportion of propositions in this text type overall refers to SoAs in the company, since the function of the text type is to summarize and evaluate the company's past development and predict its future development. There are no significant differences between the three subcorpora in this respect.

This is surprising: As we had hypothesized, there are indeed significant differences in the frequency of epistemic modal markers between English originals on the one hand and German (translated and non-translated) texts on the other. We had assumed that such differences are the result of differences in the interpersonal use of epistemic markers. This may indeed be so. However, our assumption that different frequencies of interpersonally motivated modalizations would result in differences in the distribution of the markers across tenses as well as across statements about the company and other topics was not borne out. An analysis of the exact translation relations, which we plan to conduct in the future, will hopefully give us more clarity about the exact nature of the adjustments that the translators clearly do perform.

\section{Conclusions}

The investigation presented here aimed at determining differences in the use of epistemic modal expressions in letters to shareholders written originally in American English and German as well as in texts translated from English into German. The basis of the contrastive analysis was provided by a corpus comprising English, German and translated letters to shareholders issued by multinational stock corporations. In order to identify contrasts in the frequency of use of epistemic items, all epistemic expressions were isolated through close reading. Results of this quantitative evaluation show that authors of American English letters to shareholders tend to use epistemic marking with greater frequency than German writers of this genre. Apart from differences in overall frequency, the analysis has also revealed interlingual contrasts in the linguistic devices typically used to realize epistemic modality. English has shown a clear preference for lexical verbs such as expect, believe, whereas German tends to use a greater variety of linguistic strategies to express the author's degree of commitment to what $\mathrm{s} / \mathrm{he}$ is saying. By further differentiating between epistemic items according to temporal reference and according to whether they are used in statements about the company itself or about SoAs outside the company, the analysis intended to further clarify 
the function of epistemic marking in the texts. However, the contrasts in this respect did not turn out to be significant (or only very marginally).

The analysis presented here suggests that German translations of American English letters to shareholders are adapted to the target language conventions to a great extent. Nevertheless, some impact from the English source texts can be observed in the slightly higher frequency of such expressions overall and in the more frequent use of lexical verbs. Thus, shining-through as well as cultural filtering takes place. The status of translations in this genre is thus similar to the status of translations of popular scientific articles, where also a mix of adaptation and shining-through could be observed (cf. Kranich/House/Becher 2012). Based on the present study, adaptation is, however, more pronounced in the genre letters to shareholders than in popular scientific articles.

\section{References}

Baumgarten, Nicole (2008): "Writer construction in English and German popularized academic discourse: the uses of we and wir". Multilingua 27/4: 409-438.

Baumgarten, Nicole/Özçetin, Demet (2008): "Linguistic variation through language contact in translation". In: Siemund, Peter/Kintana, Noemi (eds.): Language Contact and Contact Languages. Amsterdam, Benjamins: 293-316.

Becher, Viktor/House, Juliane/Kranich, Svenja (2009): "Convergence and divergence of communicative norms through language contact in translation". In: Braunmüller, Kurt/House, Juliane (eds.): Convergence and Divergence in Language Contact Situations. Amsterdam, Benjamins: 125-151.

Bolten, Jürgen et al. (1996): "Interkulturalität, Interlingualität und Standardisierung bei der Öffentlichkeitsarbeit von Unternehmen". In: Baumann, Klaus-Dieter/Kalverkämper, Hartwig (eds.): Fachliche Textsorten. Tübingen, Narr: 389-425.

Böttger, Claudia/Bührig, Kristin (2003): "Translating obligation in business communication". In: Perez Gonzales, Luis (ed.) (2003): Speaking in Tongues: Language across Contexts and Users. Valencia, Universidad de Valencia: 161-182.

Böttger, Claudia/Bührig, Kristin (2007): "La communication économique et les traductions". In: Behr, Irmtraud et al. (eds.) (2007): Langue, économie, entreprise. Le travail des mots. Paris, Presses Sorbonne Nouvelle: 269-283.

Byrnes, Heidi (1986): "Interactional style in German and American conversations". Text 6/2: 189-207.

Clemen, Gudrun (1997): "The concept of hedging: Origins, approaches and definitions". In: Markkanen, Raija/Schröder, Hartmut (eds.) (1997): Hedging and Discourse. Approaches to the Analysis of a Pragmatic Phenomenon in Academic Texts. Berlin, Walter de Gruyter: 235-248.

Clyne, Michael (1987): "Cultural differences in the organization of academic texts. English and German". Journal of Pragmatics 11: 211-247.

Coates, Jennifer (1995): "The expression of root and epistemic possibility in English". In: Bybee, Joan/Fleischmann, Suzanne (eds.) (1995): Modality in Grammar and Discourse. Amsterdam, Benjamins: 55-66.

Crismore, Avon/Vande Kopple, William J. (1997): "Hedges and readers: Effects on attitudes and learning". In: Markkanen, Raija/Schröder, Hartmut (eds.) (1997): Hedging and Discourse. Approaches to the Analysis of a Pragmatic Phenomenon in Academic Texts. Berlin, Walter de Gruyter: 83-113.

Declerck, Raphael (2009): "Not-yet-factual at time t: a neglected modal concept". In: Salkie, Raphael et al. (eds.) (2009): Modality in English. Theory and Description. Berlin, Mouton de Gruyter: 31-54.

Fløttum, Kjersti (1998): "Le Mot du P.D.G. - descriptif ou polémique?" In: Gambier, Yves (ed.) (1998): Discours professionnels en Français. Frankfurt, Peter Lang: 105-122.

Garzone, Giuliana (2004): "Annual Company Reports and CEO's Letters: Discoursal features and cultural markedness". In: Candlin, Christopher/Gotti, Maurizio (eds.) (2004): Intercultural Aspects of Specialized Communication. Bern, Lang: 311-341. 
Garzone, Giuliana (2005): "Letters to Shareholders and Chairman's Statements: Textual variability and generic integrity". In: Gillaerts, Paul/Gotti, Maurizio (eds.) (2005): Genre Variation in Business Letters. Bern, Lang: 179-204.

House, Juliane (1996): "Contrastive discourse analysis and misunderstanding: The case of German and English". In: Hellinger, Marlis/Ammon, Ulrich (eds.) (1996): Contrastive Sociolinguistics. Berlin, Mouton: 345-361.

House, Juliane (1997): Translation Quality Assessment. A Model Revisited. Tübingen: Narr.

House, Juliane (2006): "Communicative styles in English and German". European Journal of English Studies 10/3: 249-267.

House, Juliane (2007): "Covert translation and language contact and change". The Chinese Translators Journal 28: 17-26.

Hyland, Ken (1996): "Writing without conviction? Hedging in science research articles". Applied Linguistics 17: 433-454.

Hyland, Ken (1998): "Boosting, hedging, and the negotiation of academic knowledge". TEXT 18: 349-382.

Jenkins, Susan/Hinds, John (1987): "Business letter writing: English, French and Japanese". TESOL Quaterly 21: 327-349.

Kohut, Gary F./Segars, Albert H. (1992): "The President's Letter to Stockholders: An Examination of Corporate Communication Strategies". The Journal of Business Communication 29: 7-21.

Kranich, Svenja. (2009): "Epistemic modality in English popular scientific articles and their German translations". trans-kom. Zeitschrift für Translationswissenschaft und Fachkommunikation 2/1: 26-41.

Kranich, Svenja (2011a): "To hedge or not to hedge. The use of epistemic modal expressions in popular science in English texts, English-German translations and German original texts". Text \& Talk 31/1: 77-99.

Kranich, Svenja (2011b): "L'emploi des expressions épistémiques dans des lettres aux actionnaires en France, aux États Unis et en Allemagne". Langage et Société 137: 115134.

Kranich, Svenja/House, Juliane/Becher, Viktor (2012): "Changing conventions in EnglishGerman translations of popular scientific texts". In: Braunmüller, Kurt/Gabriel, Christoph (eds.) (2012): Multilingual Individuals and Multilingual Societies. Amsterdam, Benjamins: 315-334.

Larreya, Paul (2009): "Towards a typology of modality in language". In: Salkie, Raphael et al. (eds.) (2009): Modality in English. Theory and Description. Berlin, Mouton de Gruyter: 929.

Markkanen, Raija/Schröder, Hartmut (1997). "Hedging: A challenge for pragmatics and discourse analysis". In: Markkanen, Raija/Schröder, Hartmut (eds.) (1997): Hedging and Discourse. Approaches to the Analysis of a Pragmatic Phenomenon in Academic Texts. Berlin, Walter de Gruyter: 3-18.

Mauranen, Anna (1997): "Hedging in language revisers' hands". In: Markkanen, Raija/Schröder, Hartmut (eds.) (1997): Hedging and Discourse. Approaches to the Analysis of a Pragmatic Phenomenon in Academic Texts. Berlin, Walter de Gruyter: 115133.

McCallister, L/Bates, C. (1986): "Language as a proxy for the study of culturally based managerial values: An analysis of German and American expression". The Journal of Language for International Business 2/2: 1-14.

Palmer, Frank (2001): Mood and Modality. Cambridge: Cambridge University Press.

Pindi, Makaya/Bloor, Thomas (1987): "Playing safe with predictions: Hedging, attribution and conditions in economic forecasting". In: Bloor, Thomas/Norrish, John (eds.) (1987): Written Language Papers from the annual meeting of the British Association for Applied Linguistics held at the University of Reading, September 1986. London, CILT: 55-69.

Swales, John M. (1990): Genre Analysis: English in Academic and Research Settings. Cambridge: Cambridge University Press.

Teich, Elke (2003): Cross-linguistic Variation in System and Text. A Methodology for the Investigation of Translations and Comparable texts. Berlin/New York: Walter de Gruyter.

Van der Auwera, Johan/Schalley, Eva/Nuyts, Jan (2005): "Epistemic possibility in a Slavonic parallel corpus: A pilot study". In: Karlik, Petr/Hansen, Björn (eds.) (2005): Modality in Slavonic languages: New Perspectives. München, Sagner: 201-217. 
The use of epistemic modal markers in English and German original letters to shareholders and in English-German translations

Verstraete, Jean-Christophe (2007): Rethinking the Coordinate-Subordinate Dichotomy. Interpersonal Grammar and the Analysis of Adverbial Clauses in English. Berlin: Mouton de Gruyter.

White, Peter R. R./Sano, Motoki (2006): "Dialogistic positions and anticipated audiences - a framework for stylistic comparisons". In: Aijmer, Karin/Simon-Vandenbergen, AnneMarie (eds.): Pragmatic Markers in Contrast. Amsterdam, Elsevier: 189-214.

Wilke, Jürgen (1986): "Probleme wissenschaftlicher Informationsvermittlung durch die Massenmedien". In: Bungarten, Theo (ed.) (1986): Wissenschaftssprache und Gesellschaft. Aspekte der wissenschaftlichen Kommunikation und des Wissenstransfers in der heutigen Zeit. Hamburg, Edition Akademion: 304-318. 